\title{
«La dita Cort General representa tot lo Regne de València». El desenvolupament jurídic i parlamentari valencià entre 1238 i $1370^{1}$
}

\author{
Vicent Baydal Sala (baydal@uji.es) \\ Universitat Jaume I de Castelló
}

\begin{abstract}
En la tardor de l'any 1336, en el marc de la primera assemblea parlamentària valenciana celebrada per l'acabat de coronar Pere el Cerimoniós i del juí que s'hi inicià contra la reina viuda Elionor - per les donacions excessives i illí́cites que Alfons el Benigne li havia concedit-, els advocats de l'esmentat nou rei i de les cinc principals viles reials valencianes (Xàtiva, Morella, Morvedre, Alzira i Castelló de la Plana) proclamaren la infal-libilitat de les Corts amb les següents paraules:
\end{abstract}

La dita Cort General representa tot lo Regne de València, car en la celebració et sollempnitat d'aquella són los prelats, religiosos et persones eclesiàstiques, qui fan I e lo primer membre, los richs hòmens, cavallers et generosos, qui fan lo segon membre, los ciutadans et hòmens de viles del dit regne, qui fan lo terçer membre de la dita Cort, e no és presumpció ne semblant de veritat ne deu alcun creure que tots los membres de la Cort, en la qual ha tantes sàvies persones e moltes en dignitat e noblea constituïdes, se acordassen ne consentissen a fer tort o prejudici a alcú. ${ }^{2}$

Si les Corts representaven el variat conjunt d'estaments del regne, tant l'Església com la noblesa i els municipis reials, amb les seues corresponents subdivisions de bisbes, abats, clergues, membres d'ordes religiosos i militars, nobles, cavallers, generosos, ciutadans i vilatans, no podia ser que prengueren decisions que causaren mals i danys a ningú de manera comuna i unànime. Era, evidentment, una declaració d'intencions i de part, en un moment en què tant al monarca com als nuclis reials els interessava exhibir la unió que els dirigents del regne mostraven contra l'anterior reina, de les mans de la qual es tractava de recuperar formalment per a la Corona les esmentades cinc viles. Però era també la primera declaració conscient i poderosa - si més no la primera que hem pogut documentarde l'enorme força simbòlica i material de la institució parlamentària valenciana, que precisament en aquells moments maldava per consolidar-se després d'uns esforçats inicis vinculats a la mateixa particularitat política del Regne de València. Aquest era, de fet, l'únic territori cristià de la península Ibèrica creat al llarg del segle XIII, en un moment de gran avanç contra els musulmans, en què s'havia desplegat no només un codi jurídic propi

\footnotetext{
${ }^{1}$ El present article s'insereix en el marc del treball del grup de recerca «FORVAL. Història i Dret Forals Valencians», de la Universitat Jaume I de Castelló.

${ }^{2}$ Arxiu del Regne de València, Varia, Llibres, núm. 583, f. 31r (29-X-1336).
} 
i diferencial, sinó també un parlament representatiu que servia de fòrum de negociació i diàleg per als monarques i els líders estamentals de la terra.

En aquest sentit, precisament les consideracions i la realitat històrica dels organismes parlamentaris i legislatius s'han d'entendre en tot moment com a parts d'un procés dinàmic en constant moviment, tant en la baixa edat mitjana com encara més enllà, durant l'època moderna fins a les grans ruptures contemporànies. No debades, és això el que indiquen clarament les dos darreres grans obres d'abast europeu sobre les quals, per la seua ampla mirada i les seues innovadores i sòlides aportacions, s'hauria de fonamentar qualsevol anàlisi de les relacions polítiques de qualsevol territori baixmedieval: The Making of Polities: Europe, 1300-1500 (Watts, 2009) i Parlementer. Assemblées représentatives et échange politique en Europe occidentale à la fin du Moyen Age (Hébert, 2014). La visió detallada i comparativa d'un gran conjunt de regnes, principats, marquesats, ducats i ciutats lliures europees mostra amb nitidesa que el desenvolupament dels desiguals cossos jurídics i de les institucions collectives amb capacitat legisladora fou el resultat, distint segons els llocs, del procés d'interacció constant i variable entre els diversos agents sociopolítics de cadascun d'aquells territoris. És per això que, tot defugint de les fotos fixes i excessivament estàtiques que molts dels estudiosos contemporanis han atorgat a l'entramat jurídic i parlamentari d'època foral valenciana - de vegades bevent de manera acrítica de les opinions dels tractadistes antics-, cal que el reexaminem mitjançant una anàlisi històrica acurada.

És el que provarem de fer de manera molt sintètica en el present article per al primer segle i mig d'existència del Regne de València, des de la seua fundació en època de Jaume I fins al darrer terç del regnat de Pere el Cerimoniós, bo i tractant d'aportar certes innovacions que justament es basen en eixa mateixa observació detallada i dinàmica de les relacions polítiques i la realitat històrica.

\section{Els Furs de València i les Corts: les fonamentals decisions de Jaume I (1238-1276)}

Segons ja havien suggerit alguns autors i com planteja en aquest mateix dossier Vicent Garcia Edo (2019), tot sembla indicar que les vora 1.500 normes promulgades per Jaume I en la Costum o Costumes de València molt poc després de la conquesta de la ciutat en la tardor de 1238 estaven ja pensades per a regir no només la nova urbs cristiana, sinó també el conjunt del regne que s'estava forjant aleshores amb les terres conquerides als andalusins des que Blasco de Alagón prenguera Morella en 1231 (Garcia Edo, 1986). ${ }^{3}$ Fins i tot en aquell mateix extens text d'una banda s'indicaven «los térmens del Regne de València», des del riu Sénia fins a la serra de Biar, mentre que d'una altra banda es proclamava que a partir de llavors seria l'únic codi jurídic vàlid en el conjunt del territori: «nengunes altres costumes en la ciutat ho en alcun loch del terme altre del Regne de València en alcuna cosa no agen loch, mas per aquestes costumes la cort e-ls jutges degen los pleyts jutyar e determenar» (Garcia Edo, 2016: B). En relació amb això, cal indicar que era un codi elaborat per juristes formats a la Universitat de Bolonya (Garcia Sanz, 1996), des de la

\footnotetext{
${ }^{3}$ Emprem la forma femenina d'època medieval, «la Costum» $\mathrm{i}$ «les Costumes», que és la que apareix de manera preeminent en les compilacions forals (Garcia Edo: 2016).
} 
qual, com ja havia passat amb les Constitucions de Melfi proclamades en 1231 al Regne de Sicília per l'emperador Frederic II, es tractava d'impulsar el poder dels sobirans com si es tractaren dels antics emperadors romans (Powell, 1971). Era, per tant, una cabdal novetat politicojurídica en l'àmbit ibèric respecte a les conquestes protagonitzades entre els segles XI $\mathrm{i}$ XIII per les Corones de Portugal i Castella, que en cap cas havien generat regnes nous amb lleis pròpies i diferencials de caràcter territorial. ${ }^{4}$

Amb tot, en aquell any de 1238 la conquesta ja prevista — en els pactes anteriors fets amb els monarques de Castella per al repartiment dels dominis islàmics - encara estava lluny de completar-se, cosa que no succeí fins al 1245, bo i començant les primeres grans onades de colonització poblacional en els anys 1247 i 1248 i no expulsant al-Azraq del microestat autònom que havia mantingut al sud del nou regne fins al 1258 (Torró, 2006). En consequiència, la territorialitat i l'exclusivitat declarades inicialment per la Costum no passaven de ser un mer desig del monarca i la seua cancelleria de juristes d'inspiració bolonyesa, que xocaven amb la realitat del desenvolupament jurídic de la conquesta; de fet, tant abans com després de 1238 unes quantes desenes de localitats foren poblades mitjançant els Furs de Saragossa, especialment per part de nobles d'origen aragonés (Guinot, 2017). ${ }^{5}$ L'ús de les lleis municipals saragossanes, a més a més, donava accés a acollir-se als Furs d'Aragó, que tot just foren compilats en 1247 en un codi també de voluntat territorial - per al regne aragonés - , però gens inspirat en aquest cas en la recuperació de l'antic dret romà, sinó tot el contrari, la qual cosa posava frens a la capacitat d'actuació del monarca, en clar contrast amb la Costum o els Furs de València, que també van començar a rebre aquest darrer nom pràcticament des d'un principi (Garcia Edo, 1993; Garcia Edo, 2019).

Així les coses, per tal de superar l'heterogeneïtat foral produïda dins del mateix Regne de València, en la primavera de 1261 Jaume I prengué una segona gran decisió que afectà de manera cabdal el posterior desenvolupament jurídic i polític del territori valencià: convocà una assemblea estamental, tot sembla indicar que de caràcter parlamentari. En aquest sentit, cal dir que la promulgació reial de la Costum de València en 1238 s'havia realitzat «ab volentat e ab consell» d'alguns dels principals bisbes, nobles i ciutadans de Catalunya i Aragó (Garcia Edo, 2016: B), però no hi ha constància certa de cap reunió parlamentària amb tal consideració, ni llavors ni en els anys posteriors. De fet, tampoc cap dels documents conservats de 1261 explicita que en eixe moment s'estiguera aplegant una reunió de Corts com a tal, però, per la més que probable assistència de prelats, nobles i representants urbans i pel contingut dels temes abordats, tot sembla apuntar les connotacions parlamentàries

\footnotetext{
${ }^{4}$ Pel que fa a la Corona d'Aragó, els dominis conquerits al llarg del segle xII acabaren incorporant-se territorialment i jurídicament al Regne d’Aragó o a Catalunya, mentre que el cas del nou Regne de Mallorca creat en 1230, tot i constituir-se com un territori polític diferent, fou notablement distint del valencià, atés que les prerrogatives jurídiques atorgades per Jaume I es limitaren inicialment a unes poques desenes de franqueses, lluny de la complexitat i ambició de les Costumes o Furs de València. De fet, el menor desenvolupament jurídic i polític relatiu del Regne de Mallorca - de demografia i xarxa urbana i nobiliària molt menors que el de València - es veié en certa manera confirmat per la inexistència d'unes Corts pròpies, ja que els representants polítics balears foren convocats a les assemblees parlamentàries de Catalunya durant la baixa edat mitjana (Piña, 1993; Piña, 2001-2003; Cateura, 1997; Planas, 2017).

${ }^{5}$ En relació amb això, cal apuntar que aquest mateix autor considera, per contra, que en origen i fins al 1261 la Costum de València estava pensada per a un ús exclusivament municipal i no regnícola.
} 
de l'assemblea. En concret, Jaume I afegí alguns nous furs al codi jurídic inicial i en modificà d'altres; encarregà la seua traducció global del llatí al romanç; els confirmà i jurà observar-los; tornà a proclamar que s'havien d'observar «in omnibus causis a universis habitatoribus civitatis et totius regni Valencie» (Cortés, 2001: doc. 63) i establí que els seus successors haurien de jurar-los en una reunió de Corts celebrada a València a l'inici de cada regnat, cosa que obria la porta de totes totes a les reunions parlamentàries d'àmbit valencià (Baydal, 2014: 154-164).

L'objectiu era que els senyors que havien poblat els seus dominis amb altres cossos jurídics, bàsicament els nobles d'origen aragonés, «volrran atorgar e usar dels nostres Furs», és a dir, els de València, promulgats per Jaume I (Garcia Edo, 2016: núm. 608). Amb tot, els principals d'aquells nobles es negaren i abandonaren la reunió refermantse en la seua postura: «por ser aquel reino de la conquista de Aragón y que debía ser poblado a su fuero y repartido a los aragoneses por caballerías» (Zurita, 1610: III, cap. 66). De fet, aquella assemblea de $1261 \mathrm{amb}$ els principals representants estamentals dels colonitzadors del Regne de València, que anava molt més enllà de la simple promulgació de les Costumes en 1238 amb el consell i la voluntat dels protagonistes de la conquesta, fou l'inici d'un llarg conflicte entre els partidaris dels Furs d'Aragó i els partidaris dels Furs de València que mediatitzà el desenvolupament jurídic i polític valencià fins a la seua resolució pactada en les Corts de 1329-1330. De res no serví que en 1271 el mateix Jaume I tornara a reunir una assemblea estamental -novament enlloc s'esmenta que fóra en qualitat de Corts, però tot pareix apuntar que així va ser - per tal d'ampliar i modificar una altra vegada el codi foral valencià, que arribà ja a més de 1.500 disposicions normatives. Tot i que, segons s'hi afirmava, el rei ho havia fet «ad instanciam et requisicionem magnatum et militum, et religiosorum, ac proborum hominum civitatis et totius regni Valencie» (Cortés, 2001: doc. 90), tampoc en aquesta ocasió els senyors que empraven els furs aragonesos a títol personal i en els seus dominis renunciaren a ells ni acceptaren aquell nou intent d'extensió i territorialització dels furs valencians al conjunt del regne (Baydal, 2014: 194-202).

No debades, des d'aquelles dos reunions de 1261 i 1271 en les Corts celebrades fins al 1329-1330 es repetí pràcticament sempre la mateixa tònica: en un context de major o menor enfrontament entre els partidaris d'uns furs i dels altres - especialment greu entre 1283 i 1292-, únicament l'estament dels municipis reials donà suport ple als acords amb el monarca que es prenien en l'àmbit parlamentari, de forma que durant tot aquell període les noves normatives aprovades - si se n'aprovaven - no tenien rang foral i les Corts no podien assolir una capacitat legislativa plena. En aquest sentit, en la mateixa reunió de 1271 el monarca jurà que les noves modificacions dels Furs de València es farien sempre «cum assensu et voluntate vestra» (Alanyà, 1515: Iacobi primi, LXXXI), la qual cosa abocà al consens parlamentari per tal de desenvolupar jurídicament la normativa regnícola, però alhora el frenà mentre no es posava solució a la renyida disputa foral. En tot cas, ja quedaven assentades les bases sobre les quals es desenvoluparia jurídicament i políticament amb posterioritat el Regne de València, en un cas, com hem indicat, únic en la península Ibèrica del segle XIII: un nou territori amb un codi legislatiu propi i la capacitat de modificar-lo i ampliar-lo a través de la celebració d'unes Corts que comptaven amb la representació del conjunt de la comunitat política estamental. 


\section{Les traves imposades pel conflicte foral (1276-1327)}

Tot i que no hi ha constància documental que Pere el Gran jurara els Furs de València a l'inici del seu regnat en 1276 - ho havia fet, no obstant, com a infant en 1262-, en principi sí que intentà seguir el procediment parlamentari previst pel seu pare a l'hora d'abordar «certam reformacionem et adaptacionem fororum regni Valencie». En concret, pel novembre de 1281 convocà en Corts als principals «richis hominibus, militibus, religiosis, civibus et aliis in regno Valencie hereditatibus habentibus», encara que finalment l'assemblea a penes durà uns dies i únicament generà la modificació d'un sol fur, que a més a més fou revocada a penes dos anys després (Baydal, 2014: 252-257; Romeu, 1969: 726). De fet, la revocació es produí en el moment de l'esclat definitiu del conflicte foral, en la tardor de 1283, després que, en un context d'extrema dificultat per al monarca - que acabava de conquerir Sicília-, s'organitzara a Aragó la revolta de la Unió en defensa dels furs propis i en reivindicació de la vigència del mateix ordenament aragonés dins del territori valencià. En conseqüència, com a reacció, la ciutat de València -com a principal defensora dels furs valencians - es reuní amb el monarca i aconseguí diverses prerrogatives per a la majoria de l'estament reial: d'una banda, el permís per a conjurar-se de manera mancomunada i l'obligació expressa que cada nou rei hauria de jurar en Corts a l'inici del regnat l'ordenament foral valencià, tot i haver-ho fet anteriorment com a infant; i, d'una altra banda, la concessió del «Privilegium Magnum», un conjunt de desenes de privilegis dirigits als nuclis reials - que molt més tard serien inclosos en la compilació dels Furs e ordinacions del Regne de València, tot i no haver tingut en origen el rang de normativa foral aprovada en Corts- (Baydal, 2014: 264-283).

No obstant això, la intensitat de l'enfrontament no feu més que augmentar, com mostraren en 1286 les primeres Corts d'Alfons el Liberal, qui abandonà la ciutat de València sense haver jurat la territorialitat i exclusivitat de l'ordenament foral valencià i fou perseguit pels líders de l'estament reial fins a Borriana - de fur aragonés-, on es veié obligat a realitzar aquell jurament. No debades, l'any següent s'arribaren a produir enfrontaments militars entre els partidaris d'uns furs i dels altres i fins i tot els membres de l'estament nobiliari i de l'estament reial del Regne de València hagueren d'abandonar les Corts Generals de Montsó de 1289, per les bregues mantingudes entre ells «racione fori». Així les coses, la disputa s'hagué d'apaivagar, si més no provisionalment, a través d'una reunió a València en 1290 entre els dos estaments i el monarca, qui ordenà i feu jurar els representants dels nuclis reials que respectarien els furs aragonesos als rics hòmens, cavallers, infançons i vassalls que els observaven dins del Regne de València. De fet, fou la mateixa postura que adoptà el seu successor, Jaume II, en les seues primeres Corts valencianes de 1292, en què jurà la integritat i territorialitat dels Furs de València, «salv, emperò, ço que jurat avia als hòmens de paratge del Regne de València sobre·l Fur d'Aragó, ço és a saber, d'aquells qui·l volrien» (Baydal, 2014: 290-351). Una resolució, doncs, que deixava la situació en el mateix impàs que al principi: els furs valencians - amb el suport dels monarques i la majoria de l'estament reial- eren els únics que teòricament s'havien d'observar en el conjunt del regne, però al mateix temps es permetia la vigència dels furs aragonesos en desenes de senyorius i a nombroses persones. 
En qualsevol cas, podem extraure certes idees clares del repàs a aquell primer mig segle d'existència del Regne de València, com ara que el regnat de Jaume I posà les bases de la seua estructura jurídica i parlamentària — que podria no haver existit mai o en condicions molt diferents, com en el cas mallorquí o el dels territoris meridionals portuguesos i castellans - i que el seu mateix desenvolupament estava estretament lligat a la concreta evolució de les relacions de poder entre els diversos estaments i agents sociopolítics. En aquest sentit, cal indicar que, com hem vist, la legitimitat, territorialitat i extensió tant dels Furs de València com de les Corts valencianes foren severament qüestionades a causa de l'oposició de bona part de la noblesa d'origen aragonés, però el cert és que, amb el suport dels reis i els nuclis reials, mantingueren la força suficient per a continuar situant-se en el centre del tauler polític.

Així mateix, també cal fer notar que durant aquell període els membres dels estaments s'agruparen mancomunadament i prengueren força com a tals, amb capacitat de diàleg propi amb el rei. Hi ha nombrosos exemples d'això al llarg d'aquella etapa i durant les dècades posteriors, tant per a l'estament nobiliari com per al reial: per exemple, l'actuació de la majoria dels nobles en 1261; les peticions fetes pels cavallers aragonesos heretats al Regne de València a través d'un procurador comú en la dècada de 1280; la reunió i el privilegi obtingut en 1284 pels nuclis reials per tal d'organitzar-se de manera autònoma, fins i tot militarment; les protestes que Jaume de Xèrica va encapçalar en 1315 en nom de «tots los altres richs hòmens, cavallers e infançons del dit regne, presents e absents», contra unes cises acordades unilateralment pel rei i els municipis reials; o els nombrosos «col-loquis» $\mathrm{i}$ «tractaments» que els estaments nobiliari i reial mantingueren amb Jaume II, per separat o entre ells en 1321 i 1326, per tal de trobar una solució pactada a la quiestió foral (Baydal, 2016).

En aquest sentit, cal deixar clar que les unitats estamentals com a tals es desenvoluparen en paral·lel a les Corts i que aquestes eren l'escenari comú de debat entre el rei i el conjunt dels estaments del regne com a cos místic, en forma de cap i braços; un diàleg, no obstant això, que també es podia produir individualment amb cada estament fora del marc parlamentari. És per això que les recurrents reunions estamentals i les posteriors Juntes d'Estaments d'època moderna no foren més que la continuació i institucionalització d'aquella situació d'orígens baixmedievals, ja que els estaments tenien veu pròpia, i no eren una derivació o una emanació de les reunions de Corts, com de vegades s'ha considerat -més prompte, era al contrari-. En qualsevol cas, és evident que les Corts, per la seua representativitat general, tenien una funció simbòlica i de consens d'una força enorme (Hébert, 2014), com s'expressa clarament en el document de 1336 que hem citat al principi. En relació amb això, per tal d'arribar a l'acceptació completa de tot el que implicaven els mecanismes parlamentaris al Regne de València hagueren de resoldre's abans els greus enfrontaments ocasionats per la disputa foral.

Mentrestant, cap de les altres tres Corts, a banda de la inicial, que se celebraren durant el regnat de Jaume II obtingué la col-laboració plena de tots els estaments. En primer lloc, les de 1301-1302 únicament generaren l'anomenat «Privilegi Capitulat», un altre conjunt de disposicions sense el màxim rang legislatiu només destinades als nuclis reials — tot i que molt més avant, com passà amb els privilegis de 1283, foren incorporades a les compilacions forals - i, encara que entre elles es contenia l'obligació dels monarques 
de celebrar assemblees parlamentàries cada tres anys, la següent no s'aplegà fins al 1314 (Baydal, 2014: 376-379). En aquestes altres en un principi s'arribà a uns acords semblants, és a dir, a la preparació d'un seguit de normatives negociades exclusivament amb els municipis reials, però finalment - per causes que desconeixem - ni tan sols foren aprovades pel monarca. Més encara, les Corts de 1325, convocades pel mateix Jaume II amb la finalitat expressa de reformar l'estat del regne «de bono in melius», acabaren llicenciant-se, sembla que pels intensos desacords, novament, entre els partidaris dels Furs de València i els dels Furs d'Aragó (Baydal, 2014: 376-379; 468-476; 552-558). De fet, precisament a partir de llavors s'acabà precipitant una solució a la disputa, la qual es produí finalment ja en època d'Alfons el Benigne, en les Corts de 1329-1330, que en realitat foren les primeres de la història valenciana en què els estaments i el monarca arribaren a acords conjunts, un fet que obrí la porta a un major desenvolupament jurídic i polític del Regne de València a través del marc parlamentari.

\section{L'inici del ple desenvolupament parlamentari del Regne de València (1327-1370)}

A les darreries del regnat de Jaume II se succeïren els «col-loquis» entre els partidaris d'uns furs i els dels altres - que representaven majoritàriament bé l'estament nobiliari, bé el reial- i s'arribà a un acord entre les parts, que, no obstant això, no va poder ser formalitzat per la malaltia i mort del monarca en 1327. Així les coses, la resolució de la qüestió s'endarrerí fins al 1329-1330, amb les primeres Corts valencianes d'Alfons el Benigne, que no només hi jurà la territorialitat teòrica de l'ordenament foral valencià, sinó que estigué disposat a fer-la efectiva d'una manera tangible. De fet, aquella assemblea parlamentària fou la primera documentada — amb desenes de plecs de negociació- en què els nobles accediren a tractar afers generals del regne en el marc parlamentari, bo i trobant una solució de caràcter pactat a la disputa, que passà per l'acceptació de les Costumes i Furs promulgats en 1238, 1261 i 1271 per Jaume I i l'afegiment d'unes vora trenta rúbriques noves per part d'Alfons el Benigne, algunes de les quals garantien àmplies prerrogatives als senyors en els seus dominis —en especial «De juredicció atorgada a aquells qui no han mer imperi», que fou l'anomenada jurisdicció alfonsina-. En consequiència, la immensa majoria dels usuaris dels Furs d'Aragó renunciaren a ells durant les dos dècades immediatament posteriors i pràcticament la totalitat del regne passà a estar regida pels Furs de València (Baydal, 2016: 83-112).

Aquest fou, doncs, el principal resultat jurídic i polític de les Corts de 13291330, que, per tant, donaren peu al primer gran desenvolupament de la normativa foral valenciana, com mostra el fet que en aquell moment es consideraren les disposicions de Jaume I com els «Furs antichs» o «Furs vells» i els d'Alfons el Benigne com els «Furs nous» - sense altres lleis de rang foral entremig. ${ }^{6}$ No debades, a partir de llavors el conjunt dels estaments — que justament des d'aleshores reberen el nom de «General»- accediren a participar en els mecanismes de negociació parlamentària, tot i que encara de manera gradual i en

\footnotetext{
${ }^{6}$ Els «Furs Nous» també foren coneguts durant cert temps com «Furs de Burjassot», ja que els principals juristes i notaris del regne s'aplegaren en aquesta localitat de l'Horta de València per tal de realitzar la nova compilació foral (Baydal, 2016: 111).
} 
funció de les mateixes relacions de poder entre ells i amb el rei. Així ho indica el fet, per exemple, que Alfons el Benigne ja no tornara a aplegar Corts valencianes, en un regnat posteriorment molt marcat pel malestar creat per les grans concessions de nuclis reials que el mateix monarca feu a la seua esposa, la reina Elionor de Castella, i el fill dels dos, l'infant Ferran (Ferrer i Mallol, 1987).

En tot cas, l'inici del regnat de Pere el Cerimoniós sí que comportà un reforçament progressiu d'aquella via parlamentària, segons mostren les tres primeres Corts que reuní. En primer lloc, les de 1336 no generaren noves normes de rang foral, però serviren per a fer el jurament dels Furs de València corresponent al nou regnat i per a atorgar un privilegi que tornava a establir la triennalitat de les assemblees parlamentàries, en aquesta ocasió concedint-se no només a l'estament reial - com en 1302-, sinó al conjunt del General, concretament a «prelatis, richis hominibus, militibus, civibus et hominibus villarum totique Generali regni Valencie» (Alanyà, 1515: Petri secundi, 2a numeració, XXIX). Així mateix, també en aquella reunió s'inicià un procés judicial contra la reina Elionor per l'afer de les donacions, que acabà per resoldre's en 1339 mitjançant unes noves Corts valencianes, destinades a escollir diversos tractadors «per part dels prelats, e semblantment çertes persones per part de richs hòmens e de cavallers, e semblantment per part de la ciutat e de les viles reals del Regne de València», ${ }^{7}$ per tal que aconsellaren al monarca sobre la qüestió. Finalment, a més a més, en les Corts de 1342 per primera vegada els tres estaments -incloent-hi l'eclesiàstic i no només el reial i el nobiliari com en 1329-1330 - tractaren de negociar i obtindre nous furs aprovats pel monarca i el General, tot i que, ateses les discrepàncies que s'hi produïren entre ells, el Cerimoniós allegà que «no hi poria res mudar sens consentiment de la Cort» i es limità a acceptar únicament algunes peticions realitzades pels nuclis reials i promulgar-les no amb rang foral, sinó com a simples «provisions»o «ordinacions» (Baydal, 2011: 559-574; 602-618). ${ }^{8}$

Més encara, la revolta de la Unió de 1347-1348 contra el monarca - motivada pels abusos comesos pels oficials reials i les actuacions i comportaments autoritaris del Cerimoniós i els seus consellers - estigué a punt de trencar aquell camí gradual de negociacions parlamentàries que s'havia iniciat en 1329-1330. En aquest sentit, tot i que el greu conflicte, que comportà una terrible guerra civil, es tancà justament a través d'unes Corts, les de 1349, cal dir que aquestes estaven evidentment controlades i dirigides pel monarca, en un context d'extrema repressió contra els vençuts. En qualsevol cas, la tria d'aquell escenari parlamentari i l'aprovació de noves disposicions forals que havien de ser observades de manera general -i que foren ara anomenades «Furs novells», després dels «Furs antichs» de 1238, 1261 i 1271 i els «Furs nous» de 1329-1330-, mostra, com ja s'havia manifestat en 1336, l'enorme força representativa que havien assolit les Corts com a símbol màxim del conjunt del regne en estreta unió amb el monarca. Però, per això mateix, per tal d'evitar les negociacions collectives, malgrat les peticions perquè es tornara a aplegar en assemblea parlamentària «tot lo General del regne, axí lo braç dels

\footnotetext{
${ }^{7}$ Arxiu Municipal de València, Manuals de Consells, A-3, f. 262v (16-II-1339).

${ }^{8} \mathrm{Cal}$ indicar que també en 1340 foren reunits els tres estaments valencians, tot i que, segons indica la documentació, no en qualitat de Corts, sinó de Parlament, potser perquè l'únic objectiu de l'assemblea era el d'aprovar un subsidi per a la defensa del regne contra els marínides, sense negociar en absolut noves normes jurídiques (Baydal, 2011: 590-601).
} 
prelats e clergues com lo braç dels nobles, cavallers e generoses, com encara lo braç de les ciutats, viles e lochs reals e altres del dit Regne de València», ${ }^{9}$ Pere el Cerimoniós tractà d'eludir-les durant els anys següents tant com pogué, amb l'única excepció de les Corts de 1354, exclusivament convocades per a fer jurar l'infant Joan com a hereu, davant el perill que el mateix monarca morira en l'expedició de conquesta de Sardenya que estava a punt d'encapçalar (Baydal, 2011: 674-677, 720-721).

Amb tot, l'inici de la guerra contra Pere el Cruel de Castella en 1356, amb la seua llarga extensió fins a 1369 i sobretot amb les seues ingents exigències fiscals per tal de pagar els exèrcits que havien de fer front a les recurrents invasions de les hosts castellanes, feu que la via de la negociació parlamentària acabara agafant força, a causa de les necessitats del rei i amb la participació activa de tots els estaments. De fet, en les primeres de les set Corts celebrades durant aquell període, en 1357-1358, 1360, 1362-1363, 1364, 1365, 1367 i 1369-1370, s'explicità que les noves disposicions jurídiques aprovades amb el rang de fur s'havien aprovat «aprés molts tractaments fets en la dita Cort, ab acort, consell e exprés consentiment» de tots els assistents (Alanyà, 1482: 1358, Proemi), alhora que també es concediren alguns privilegis a petició del conjunt dels «prelatorum, personarum ecclesiasticarum, nobilium, militum et generosorum ac sindicorum universitatum civitatum et villarum regni Valencie» (Arinyo, 1515: Petri secundi, LXXXI). En les de 1360, en canvi, no s'arribà a cap acord legislatiu, però en les de 1362-1363, tot i tancar-se apressadament per les urgències militars i anotar-se en els registres de la cancelleria reial que els «capítols» aprovats, fins a quaranta-cinc, eren «en loch de furs» (Baydal, 2011: 769), un d'ells manifestà amb total rotunditat el paper cabdal que les Corts havien assolit en el seu paper com a marc principal de les negociacions politicofiscals entre el rei i el General dels estaments:

Que, a bé de la cosa pública del Regne de València, façats privilegi e ordenació general al dit regne de tenir e celebrar en lo dit Regne de València de tres en tres anys personalment Corts Generals als habitants en lo dit regne, e que açò jurets vós, senyor, e juren vostres successors reys en lo començament de lur regiment. E si les dites coses no seran feytes ab acabament, vós ne los vostres successors reys no puxats fer o demanar subsidi, do o ajuda al dit vostre regne o alcun braç de aquell o singulars dels dits braços en general ne special (Garcia Edo, 2016: núm. 1907).

Així mateix, encara que no apareguen en les compilacions conegudes ni se n'hagen documentat, també en les Corts de 1364, celebrades a Cullera en ple assetjament castellà de la ciutat de València (Muñoz Pomer, 1985), es degueren aprovar normes de rang foral - potser temporals_-, segons es recordava al Cerimoniós en una assemblea posterior: «per fur per vós feyt en les Corts per vós, senyor, celebrades en Cullera» (Garcia Edo, 2016: núm. 1938). Igualment, en les celebrades a l'any següent, aquesta vegada «en lo setge de Morvedre», s'aprovaren algunes poques disposicions relacionades amb el desenvolupament de la guerra (Romeu, 1981; Garcia Edo, 2016: núms. 1919-1921), sense especificar-ne el rang, i en les de 1367, tot i que no se n'atribuí cap en les compilacions posteriors, es

\footnotetext{
${ }^{9}$ Arxiu Municipal de València, Manuals de Consells, A-11, mà 1a ,f. 25v (4-XI-1353).
} 
promulgaren, si més no, un fur temporal per a no deixar eixir del regne cap «moro, ne mora, ne subay» durant deu anys i un altre de perpetual, per tal d'assegurar la transmissió i conservació dels llibres, protocols i escriptures dels notaris després de la seua mort. ${ }^{10}$ Finalment, en les Corts de 1369-1370 es promulgaren una vintena de «capítols de tots los tres braços», que en la següent assemblea de 1371 foren també qualificats de furs: «per fur novell per vós, senyor, fet en les dites Corts celebrades en la vila de Sent Matheu en l'any prop passat» (Candela, 2006; Garcia Edo, 2016: núm. 1954).

En definitiva, en aquell període es normalitzaren definitivament els mecanismes parlamentaris, amb la consegüent producció legislativa, que continuaria progressant durant la resta de l'edat mitjana. D'aquesta manera, a través del llarg procés evolutiu que hem vist, que arrancava en les decisions preses per Jaume I a l'hora d'organitzar el Regne de València mitjançant un codi jurídic i unes Corts pròpies i acabava amb la plena consolidació d'aquests dos mateixos elements, s'assentaren, per exemple, les bases per als procediments de resolució de la crisi successòria iniciada en 1410, amb la mort de Martí l'Humà. No debades, en ella intervingueren els líders de les comunitats politicoterritorials que havien desenvolupat amb anterioritat complexes estructures parlamentàries i representatives a Aragó, Catalunya i València, que foren, en darrer terme, les legitimadores de l'elecció d'un nou monarca entre els diversos pretendents a la Corona.

\section{Pensar els Furs i les Corts històricament}

Com hem vist, l'anàlisi acurada de l'evolució jurídica i parlamentària del Regne de València, a través de l'examen de la naturalesa de les normatives progressivament aprovades i les característiques de les assemblees parlamentàries reunides, aporta importants matisos i novetats al coneixement dels Furs i les Corts valencianes dels segles XIII i bona part del XIV. De fet, aquestes aportacions casen sòlidament amb les línies que tracen els esmentats John Watts (2009) i Michel Hébert (2014) en les seues cabdals obres sobre el desenvolupament polític i parlamentari dels territoris europeus baixmedievals. En aquest sentit, el primer mostra clarament com la gran conflictivitat entre els diversos agents sociopolítics produïda a tot arreu entre finals del dos-cents i finals del tres-cents no només va generar greus enfrontaments, sinó també noves estructures polítiques i institucionals en molts nivells, com ara a escala regnícola, amb una territorialització progressiva dels ordenaments jurídics i un avanç de potents organismes de negociació com les Corts. Per la seua banda, el segon incideix en el fet que, tot i les evidents diferències territorials, precisament durant aquell mateix període les assemblees parlamentàries prengueren força com les grans institucions de representació i de govern col·lectiu, tot obligant els reis i el conjunt dels regnes amb les seues decisions debatudes i consensuades.

En relació amb tot això, resulta evident que, per a conéixer amb major profunditat l'evolució, els trets i la posició de l'estructura jurídica i parlamentària valenciana en relació amb altres llocs de la península Ibèrica i Europa durant la baixa edat mitjana, caldrà

\footnotetext{
${ }^{10}$ Així ho indica clarament el procés de Corts corresponent: ACA, Reial Cancelleria, Processos de Corts, 6, f. 127v (20-III-1367) i 133r (22-III-1367). De fet, el fur perpetual coincideix amb el darrer atribuït a les Corts de 1365 en la compilació de Gabriel Lluís Arinyo (1482), qui degué errar en la seua ordenació i datació.
} 
continuar realitzant la mateixa anàlisi minuciosa i dinàmica dels Furs i les Corts posteriors, en funció de les canviants relacions de poder i les seues concretes materialitzacions, entre finals del segle XIV i finals del xv. Un treball a llarg termini i del qual encara queda moltíssim camí per recórrer.

\section{BIBLIOGRAFIA}

Alanyà, L. (1515): Aureum opus regalium privilegiorum civitatis et regni Valentiae, València, Diego de Gumiel.

ARINYo, G. L. (1482): Furs e ordinacions fetes per los gloriosos reys de Aragó als regnícols del Regne de València, València, Lambert Palmar.

BAYDAL, V. (2011): Els fonaments del pactisme valencià. Sistemes fiscals, relacions de poder i identitat col-lectiva al Regne de València (c. 1250-1365), Barcelona, Universitat Pompeu Fabra, tesi doctoral.

BAYDAL, V. (2014): Guerra, relacions de poder i fiscalitat negociada: els orígens del contractualisme al Regne de València (1238-1330), Barcelona, Fundació Noguera.

BAYDAL, V. (2016): Els valencians, des de quan són valencians?, Catarroja, Afers.

Candela, B., Cortes Valencianas de finales del reinado de Pedro IV: Actas de 1369, 1371 y 1375, Alacant, 2006.

CAteura, P. (1997): Mallorca en el segle XIII, Palma, El Tall.

CoRTÉs, J. (2001): Liber privilegiorum civitatis et regni Valencie, València, Publicacions de la Universitat de València.

Ferrer i Mallol, M. T. (1987): «Causes i antecedents de la guerra dels dos Peres», Boletín de la Sociedad Castellonense de Cultura, 63, 445-508.

Garcia Edo, V. (1986): «Blasco de Alagón», Boletín de la Sociedad Castellonense de Cultura, 62, 392-395.

Garcia Edo, V. (1993): «Origen i expansió dels Furs o Costum de València durant el regnat de Jaume I», Boletín de la Sociedad Castellonense de Cultura, 69, 175-200.

Garcia Edo, V. (2016): Furs de València (1238-1645), València, Generalitat Valenciana.

Garcia Edo, V. (2019): «La "Costum de la ciutat i regne de València" de 1238», Anuari de l'Agrupació Borrianenca de Cultura, 30, XX-XX.

Garcia Sanz, A. (1996): «El jurista Pere Albert i la seva obra», Estudis històrics $i$ documents dels Arxius de Protocols, 14, 7-38.

Guinot, E. (2017): «De los fueros locales al Fuero de Valencia en el marco del proceso de instauración de la sociedad feudal del siglo XIII en el Reino de Valencia», Studia historica. Historia medieval, 35-2, 37-62.

HÉBERT, M. (2014): Parlementer. Assemblées représentatives et échange politique en Europe occidentale à la fin du Moyen Age, París, Éditions de Boccard.

Muñoz Pomer, R. (1985): «Las Cortes de Cullera-Valencia de 1364», Saitabi, 35, 87-94.

Pastor, F. J. (1547-1548): Fori Regni Valentiae, València, Johan Mey.

PIÑA, R. (1993): El derecho histórico del Reino de Mallorca, Palma, Cort.

PIÑA, R. (2001-2003): «El "Regnum Balearium". De la participació a les Corts catalanes a la consolidació dels parlaments insulars», Ius fugit, 10-11, 721-733.

Powell, J. M. (1971): The Liber Augustalis or Constitutions of Melfi Promulgated By the Emperor Frederick II for the Kingdom of Sicily in 1231, Syracuse, Syracuse University Press.

Planas, A. (2017): «Las relaciones entre rey y reino en un territorio sin Cortes: el caso de Mallorca», J. Baró (ed.), Repensando la articulación institucional de los territorios sin representación en Cortes en el Antiguo Régimen en la Monarquía Hispánica, Madrid, Marcial Pons, 97-120.

Romeu, S. (1969): «Cortes de Valencia de 1281», Anuario de Historia del Derecho Español, 39, 725-728.

Romeu, S. (1981): «Cortes en "lo setge de Murvedre" de 1365», I Congreso de Historia del País Valenciano, València, Universitat de València, vol. 2, 619-624.

TORRó, J. (2006): El naixement d'una colònia. Dominació i resistència a la frontera valenciana (12381276), València, Publicacions de la Universitat de València. 
Watts, J. (2009): The Making of Polities: Europe, 1300-1500, Cambridge, Cambridge University Press. [Traducció al castellà en Watts, J. (2016): La formación de los sistemas políticos: Europa (13001500), València, Publicacions de la Universitat de València].

Zurita, J. (1610): Anales de la Corona de Aragón, Saragossa, Lorenzo Robles.

\section{BIONOTA}

\section{Vicent Baydal}

És llicenciat en Història per la Universitat de València i doctor en Història Medieval per la Universitat Pompeu Fabra de Barcelona. Després d'haver exercit com a investigador postdoctoral a la Universitat d'Oxford, en l'actualitat és professor d'Història del Dret del Departament de Dret Privat de la Universitat Jaume I de Castelló. Coordinador del Grup de Recerca «FORVAL. Història i Dret Forals Valencians», és autor de més de quaranta publicacions acadèmiques centrades en temes diversos, com ara l'evolució de la fiscalitat pública, les relacions polítiques i les assemblees parlamentàries del Regne de València durant la baixa edat mitjana. També és especialista en l'anàlisi dels fenòmens identitaris i ha publicat llibres com Els valencians, des de quan són valencians? (Afers, 2016) i Del Sénia al Segura. Breu història dels valencians (Drassana, 2018). Compagina el seu treball acadèmic i universitari amb una activa tasca de divulgació històrica en internet i els mitjans de comunicació. 